\title{
Relationship of electronic device usage with obesity and speech delay in children
}

\author{
SHAZAN BORAJY1, A-F DANIA ALBKHARII, A-F , HUDA TURKISTANI ${ }^{2, A-F}$, REHAM ALTUWAIRIQI', A-F \\ ORCID ID: 0000-0003-4651-2485 \\ KHALID ABOALSHAMAT ${ }^{3, A-F}$, TAHIR ALTAIB², A-F, WIJDAN ALMEHMAN², A-F
}

${ }^{1}$ Batterjee Medical College, Jeddah, Saudi Arabia

${ }^{2}$ Ministry of Health (MOH), Jeddah, Saudi Arabia

${ }^{3}$ Dental Public Health Division, Preventative Dentistry Department, College of Dentistry, Umm Al-Qura University, Makkah, Saudi Arabia

A - Study Design, B - Data Collection, C - Statistical Analysis, D - Data Interpretation, E - Manuscript Preparation, F - Literature Search, G - Funds Collection

Summary Background. Smart device usage has become favorable among children worldwide.

Objectives. The study aimed to identify the relation between usage of electronic devices with obesity and speech delay.

Material and methods. A cross-sectional study was conducted among 452 healthy children (18 months to 14 years old) from pediatric clinics of the Ministry of Health (MOH), Jeddah, Saudi Arabia. Data was collected from June to July 2018. Analysis included linear regression, logistic regression, chi-square, $t$-test and ANOVA.

Results and discussion. Male participants totalled 57.7\% and females 42.3\% (mean age 82.27 months) (SD = 40.18). Mean duration of usage: 3.1 hours (SD = 2.58) per day. Among toddlers only, $31.1 \%$ had speech delay. The results showed no relation between the duration of smart device usage and obesity ( $p$-value $=0.904)$ or speech delay ( $p$-value $=0.538)$. Duration of usage was not influenced by gender or parents' marital status; however, children who live with both parents spent less time on smart devices than others. The smart device most used was a tablet (47\%), and the main usage was primarily entertainment (60.8\%) and games (47.6\%). Only $57.8 \%$ reported having parental supervision. Among children, $59.3 \%$ eat chips and $48.9 \%$ eat candy as snacks during usage. Among parents, $71.5 \%$ believe devices reduce children's physical activities, $64.8 \%$ believe that the smart device is a problem, $62.5 \%$ of parents should control time of use, and $60.5 \%$ believe that their children are attached to the devices.

Conclusions. There is no association between the duration of using smart devices and obesity, nor speech delay. Future directions and recommendations should be discussed.

Key words: obesity, child, electronics.

Borajy S, Albkhari D, Turkistani H, Altuwairiqi R, Aboalshamat K, Altaib T, Almehman W. Relationship of electronic device usage with obesity and speech delay in children. Fam Med Prim Care Rev 2019; 21(2): 93-97, doi: https://doi.org/10.5114/fmpcr.2019.84542.

\section{Background}

According to the American Academy of Pediatrics, new media devices, such as televisions with video gaming, smart tablets and smartphones, now occupy a wide array of children's lives, becoming one of the most influential mediums [1]. According to the Kaiser Family Foundation, American children aged 8 to 10 years spend, on average, eight hours a day using one of a range of electronic items [2]. Even worse, older children and teenagers spend more than 12 hours per day on electronic devices [2].

When electronic devices were first invented, they were meant to serve as an end to the communication barriers between settlements often separated by vast distances. It was hard to expect the devastating effects that such devices might have on the health of adults and, even more so, on the health of children. In fact, a number of articles in literature on the subject now highlight the importance of policy makers and parents guiding children's use of new media devices and social media, as there is a probability that the child will encounter one of the many potential negative effects from such use, including eating problems, academic challenges or being exposed to unsuitable or overtly sexual content $[3,4]$. It should be noted that according to a recent systematic review, the majority of these studies were conducted to assess the negative effects of TV or video gaming on children [5]. Only $4 \%$ of the extracted studies assessed the health impact of smart devices, such as phones, tablets and laptops, on children's health [5].

Even fewer studies have investigated the relationship between the use of these new electronic devices and childhood obesity. A Saudi study found that there was a relationship between children spending more than two hours per day on smart devices and body mass index (BMI), indicating that smart device use may increase the risk of obesity [6]. However, the study did not exclude children with chronic diseases that can significantly increase BMI. Furthermore, the data in that study was in a categorical format using two hours as a cutoff point. More accurate results can be obtained using a linear regression model when the data being analyzed is in a continuous format.

Several other studies have found a significant relationship between watching TV and a higher BMI in Saudi Arabia [7] and in other countries around the world [8-10], where children are less active, consume fewer vegetables and eat more high-calorie food. One study indicated that the time spent actually watching TV was unrelated to BMI. But rather, the attention given while watching TV's was in fact directly related to a higher BMI in older children [11]. Nevertheless, only one study, conducted in Al-Agha in 2016, included smart devices in relation to BMI. 
Moreover, a study of toddlers in Korea indicated that watching TV for more than two hours per day is related to speech delays [12]. Another study in the United States found that children's vocabularies and expressions depended mainly on the content of TV shows, with some of the effects being positive and some negative [13], although other studies indicate that watching TV can result in attention problems by the age of 7 [14]. Again, however, no studies looked at the relationship between smart devices and speech delays, especially for toddlers.

\section{Objectives}

This study therefore aimed to identify the relationship between usage of electronic devices and their content with obesity and speech difficulties in kindergartners starting from 18 months (1), school aged children - before adolescence (2), and adolescence - less than 18 years of age, in Jeddah, Kingdom of Saudi Arabia (KSA).

\section{Material and methods}

\section{Participants}

This was a cross-sectional study conducted from June 2018 to July 2018. Participants were recruited from general pediatric clinics in governmental hospitals in Jeddah, KSA, to investigate the relationship between the use of electronic devices and their content on obesity and speech delays among healthy kindergartners up to adolescent children. A quota sampling technique was used to collect data based on an equal ratio of males and females. Only healthy kindergartners and adolescent children were included. Exclusion criteria included children who were younger than 18 months or older than 14 years, as well as those with chronic illnesses that can significantly affect body weight. Also excluded were children on steroid therapy and children with ADHD; autism; endocrinological disorders; cardiac, renal, respiratory, liver, neurological or immunological diseases; mental retardation, developmental delays, hearing impairments or family history of those same medical issues; and genetic or metabolic disorders that affect body weight.

A sample size calculation formula using a precision degree of $5 \%$, expected prevalence of $50 \%$ and confidence level of $95 \%$ indicated that the minimum requirement for this study was 385 participants/parents of children.

\section{Data collection}

Data was collected by medical professionals through a self-reported, hard-copy questionnaire and combined with the child's measured weight, height and speech ability. After obtaining written consent, the questionnaire was given to parents visiting pediatric clinics at designated hospitals. The parents were instructed to answer the questionnaire on their own while the child's measurements were being taken by medical professionals. No age criteria were implicated to parents of children who agreed to participate in this research.

The questionnaire had four parts, where the first three were completed by parents. Part one was demographic data collected through six questions, including age, gender, parents' educational levels, family income and type of primary caregiver. Part two comprised nine questions about the child's electronic device usage. Part three included four questions about the child's lifestyle. Finally, the last section, part four, was completed by the research team to record the measurements of the child's weight, height and speech ability. Weight was rounded off to the nearest 0.1 kilogram (kg), using a single scale. Height was measured without shoes and was rounded off to the nearest centimeter $(\mathrm{cm})$ using a manual scale with a height rod. Weight and height were taken to calculate BMI as a tool for screening for obesity, which is defined as weight in kg divided by height in square meters, bearing in mind that BMI is not considered as an anthropometric measure in very young children. BMI was used mainly in its continuous format for more accurate analysis. Speech abilities were recorded using speech and language screening guidelines [15] for normal or delayed speech, as noted in Table 1, by pediatric residents. It should be noted that speech delay assessment was conducted only on toddlers less than 37 months old.

Table 1. Speech and language screening guidelines for a child to be classified as delayed speech according to Nelson Textbook of Pediatrics

\begin{tabular}{|l|l|l|}
\hline $\begin{array}{l}\text { Child's age } \\
\text { in months }\end{array}$ & Receiving & Expressing \\
\hline 15 & $\begin{array}{l}\text { cannot point or look at } \\
10 \text { objects or less }\end{array}$ & using less than 3 words \\
\hline 18 & $\begin{array}{l}\text { cannot keep track with } \\
\text { a simple order or task, } \\
\text { such as "bring your bag" }\end{array}$ & $\begin{array}{l}\text { not saying mom, dad or } \\
\text { any other name }\end{array}$ \\
\hline 24 & $\begin{array}{l}\text { cannot recognize body } \\
\text { parts if named nor can } \\
\text { tell what's in a picture }\end{array}$ & using less than 25 words \\
\hline 30 & $\begin{array}{l}\text { does not respond to } \\
\text { questions verbally or } \\
\text { by shaking head or } \\
\text { nodding }\end{array}$ & $\begin{array}{l}\text { cannot say a simple } \\
\text { phrase or sentence of } \\
2 \text { words }\end{array}$ \\
\hline 36 & $\begin{array}{l}\text { cannot follow orders or } \\
\text { directions of more than } \\
1 \text { step }\end{array}$ & $\begin{array}{l}\text { does not have 200 } \\
\text { or more words in vo- } \\
\text { cabulary and would not } \\
\text { require any prompting }\end{array}$ \\
\hline
\end{tabular}

Any recognizable information was excluded so that all collected data and participants were anonymous. Ethical approval was obtained from the Saudi Ministry of Health (MOH), Saudi Arabia, Jeddah, on September 19, 2018, with approval number A00623, which stated its validity for one year and gave approval for questionnaire distribution and data collection at different governmental hospitals. Ethical approval was rechecked by the scientific committee and ethical approval committee with rechecking number: $\mathrm{H}-02-\mathrm{J}-002$, with scientific research number: 00957.

Analyses were conducted using SPSS version 21 (IBM, Armonk, NY, USA), and the linear regression test was used to analyze the relationship between duration of smart device usage and BMI. $t$-test and ANOVA were used to compare the duration spent on smart devices between different groups, and chi-square was used to compare the content of smart devices between different groups. Logistic regression was used to find the relationship between smart device use and speech ability. Chi-square and Fisher's exact test were used to compare speech delay with demographic variables. A statistical significance level of 0.05 was used.

\section{Results}

A total of 452 participants answered the questionnaires, with a mean $(\mathrm{m})$ age of 82.40 months and standard deviation (SD) of 39.95. Table 2 shows the demographic variables, while Table 3 demonstrates participants' BMI and lifestyle information for participants. 


\begin{tabular}{|c|c|c|c|}
\hline Demographic & & Count (\%) & Mean (SD) \\
\hline \multirow[t]{2}{*}{ Gender } & male & \begin{tabular}{|l}
261 \\
$(57.74 \%)$ \\
\end{tabular} & \\
\hline & female & $\begin{array}{l}191 \\
(42.26 \%)\end{array}$ & \\
\hline \multirow{3}{*}{$\begin{array}{l}\text { Mother's } \\
\text { education } \\
\text { level }\end{array}$} & $\begin{array}{l}\text { less than high } \\
\text { school }\end{array}$ & $\begin{array}{l}48 \\
(10.62 \%)\end{array}$ & \\
\hline & high school & $\begin{array}{l}137 \\
(30.31 \%)\end{array}$ & \\
\hline & college or more & $\begin{array}{l}267 \\
(59.07 \%) \\
\end{array}$ & \\
\hline \multirow[t]{3}{*}{$\begin{array}{l}\text { Father's edu- } \\
\text { cation level }\end{array}$} & $\begin{array}{l}\text { less than high } \\
\text { school }\end{array}$ & $\begin{array}{l}40 \\
(8.85 \%) \\
\end{array}$ & \\
\hline & high school & $\begin{array}{l}100 \\
(22.12 \%) \\
\end{array}$ & \\
\hline & college or more & $\begin{array}{l}312 \\
(69.03 \%) \\
\end{array}$ & \\
\hline \multirow[t]{3}{*}{$\begin{array}{l}\text { Family in- } \\
\text { come (Saudi } \\
\text { Riyal) }\end{array}$} & $\begin{array}{l}\text { less than } 5,000 \\
\text { (equivalent to } \\
1332.97 \text { USD) }\end{array}$ & $\begin{array}{l}86 \\
(19.03 \%)\end{array}$ & \\
\hline & $\begin{array}{l}5,000-15,000 \\
\text { (equivalent to } \\
1332.97- \\
-39989025 \text { USD) }\end{array}$ & $\begin{array}{l}232 \\
(51.33 \%)\end{array}$ & \\
\hline & $\begin{array}{l}\text { more than } 15,000 \\
\text { (equivalent to } 39 \\
989025 \text { USD) }\end{array}$ & $\begin{array}{l}134 \\
(29.65 \%)\end{array}$ & \\
\hline \multirow[t]{2}{*}{$\begin{array}{l}\text { Child lives } \\
\text { with }\end{array}$} & both parents & $\begin{array}{l}387 \\
(85.62 \%)\end{array}$ & \\
\hline & $\begin{array}{l}\text { one parent or } \\
\text { guardian(s) }\end{array}$ & $\begin{array}{l}65 \\
(14.38 \%) \\
\end{array}$ & \\
\hline \multirow[t]{2}{*}{$\begin{array}{l}\text { Parents' } \\
\text { marital status }\end{array}$} & married & \begin{tabular}{|l|}
388 \\
$(85.84 \%)$ \\
\end{tabular} & \\
\hline & $\begin{array}{l}\text { divorced/one or } \\
\text { both deceased }\end{array}$ & \begin{tabular}{|l}
64 \\
$(14.16 \%)$ \\
\end{tabular} & \\
\hline Siblings & & & $2.53(1.97)$ \\
\hline Weight (kg) & & & $27.57(15.95)$ \\
\hline Height (cm) & & & $116.6(21.71)$ \\
\hline
\end{tabular}

\begin{tabular}{|l|l|l|l|}
\hline \multicolumn{3}{|c|}{ Table 3. BMI and lifestyle information for participants } \\
\hline & & Count (\%) & Mean (SD) \\
\hline BMI & & & 19.57 (9.17) \\
\hline Lifestyle & & & Mean (SD) \\
\hline $\begin{array}{l}\text { Number of } \\
\text { meals/day }\end{array}$ & & & $2.77(0.92)$ \\
\hline $\begin{array}{l}\text { Number of } \\
\text { snacks/day }\end{array}$ & $\begin{array}{l}\text { less than } 30 \\
\text { Physical } \\
\text { activity/day }\end{array}$ & $176(38.94 \%)$ & \\
\hline & $\begin{array}{l}\text { more than } \\
30 \text { min }\end{array}$ & $276(61.1 \%)$ & \\
\hline
\end{tabular}

The results showed that children's smart devices usage was $m=3.1$ hours with SD of 2.58 hours per day. Among the children, 403 (89.16\%) used smart devices, and 239 (52.88\%) of the children used personal smart devices. Among the parents, 355 $(78.54 \%)$ use their smart devices in front of their children. The average number of smart devices per family was found to be $m$ $=4.88, \mathrm{SD}=2.88$.

When we assessed speech delay, we only included data from children who were 36 months old or younger $(n=74)$.
Among those, 23 children (31.1\%) had speech delay. Those children (toddlers) had $m=3.31, \mathrm{SD}=2.56$ hours of smart device usage, which was not significantly different from children older than 36 months ( $m=3.06, \mathrm{SD}=2.59)$ after using $t$-test. Using chi-square and Fisher's exact test, the presence of speech delay was not significantly different between the demographic variables, including gender, mother's educational level, father's educational level, family income, children living with both parents or otherwise and the marital status of parents.

Using a simple linear regression for all participants, there was no significant relationship found between children's duration of smart device usage and $\mathrm{BMI}(\mathrm{F}(1,450)=0.14, p=0.904)$, nor with number of meals $(F(1,450)=3.39, p=0.066)$, but there was a significant relationship with the number of snacks per day $(\mathrm{F}(1,450)=36.66, p<0.001, R$-squared $=0.075)$. Using logistic regression, there was no significant relationship $(p=0.565)$ between children's duration of smart device usage and speech delay among children who were 36 months old or younger.

Using the $t$-test, the duration spent on smart devices was not found to be significantly different by gender or parent's marital status. However, it was found that children who lived with both parents spent significantly less time on smart devices ( $m=2.95, \mathrm{SD}=2.4$ ) than those who lived with one parent or other family member or guardian $(m=4.02, S D=3.36),(t(75.35)$ $=-2.45, p=0.016$ ).

The behaviors of children who use smart devices $(n=403)$ and their parents are detailed in Table 4.

\begin{tabular}{|c|c|c|}
\hline & & $\begin{array}{l}\text { No. of those who } \\
\text { use the device (\%) }\end{array}$ \\
\hline \multirow{3}{*}{$\begin{array}{l}\text { Type of used } \\
\text { devices }\end{array}$} & tablet & $192(47.6 \%)$ \\
\hline & phone & $132(32.8 \%)$ \\
\hline & smart tv & $141(35.0 \%)$ \\
\hline \multirow{3}{*}{$\begin{array}{l}\text { Time spent using } \\
\text { smart devices }\end{array}$} & day & $228(56.6 \%)$ \\
\hline & night & $194(48.1 \%)$ \\
\hline & before bed & $131(32.5 \%)$ \\
\hline \multirow{5}{*}{$\begin{array}{l}\text { Content of smart } \\
\text { devices used by } \\
\text { child }\end{array}$} & educational & $120(29.8 \%)$ \\
\hline & entertainment & $245(60.8 \%)$ \\
\hline & songs & $157(39.0 \%)$ \\
\hline & games & $192(47.6 \%)$ \\
\hline & other & 25 (6.2\%) \\
\hline Parental control & yes & $233(57.8 \%)$ \\
\hline \multirow{4}{*}{$\begin{array}{l}\text { Reason for parents } \\
\text { giving children } \\
\text { smart devices }\end{array}$} & child diversion & $135(33.5 \%)$ \\
\hline & child entertainment & $290(72.0 \%)$ \\
\hline & child education & $133(33.0 \%)$ \\
\hline & child reward & 74 (18.4\%) \\
\hline \multirow{4}{*}{$\begin{array}{l}\text { During smart de- } \\
\text { vice usage, child's } \\
\text { consumption }\end{array}$} & soft drinks & $62(15.4 \%)$ \\
\hline & candy & $197(48.9 \%)$ \\
\hline & chips & 239 (59.3\%) \\
\hline & $\begin{array}{l}\text { the child does not } \\
\text { eat snacks during } \\
\text { smart device usage }\end{array}$ & $86(21.3 \%)$ \\
\hline
\end{tabular}

Using chi-square, there was no significant difference found between male and female children in regard to the content of smart devices used except for listening to songs, as girls (45\%) tended to use smart devices to listen to music more than boys $(27.2 \%)\left(\chi^{2}(2)=15.98, p<0.001\right)$. 
Table 5 details the perceptions and attitudes of parents toward their children's use of smart devices.

\begin{tabular}{|c|c|}
\hline Statement & $\begin{array}{l}\text { No. agreeing } \\
\text { (\%) }\end{array}$ \\
\hline Smart devices are good for educating my child & $252(62.5 \%)$ \\
\hline Smart devices can help my child with speech & $180(44.7 \%)$ \\
\hline Smart devices make my child eat more snack & $187(46.4 \%)$ \\
\hline $\begin{array}{l}\text { Smart device usage decreases my child's physical } \\
\text { activity }\end{array}$ & $288(71.5 \%)$ \\
\hline Smart device usage by my child is a problem & $261(64.8 \%)$ \\
\hline $\begin{array}{l}\text { Parents should allocate specific time limitations } \\
\text { for the use of smart devices }\end{array}$ & $252(62.5 \%)$ \\
\hline My child is attached to smart devices & 244 (60.5\%) \\
\hline
\end{tabular}

\section{Discussion}

Our result showed that there was no significant relationship between the time spent using smart devices and increased $\mathrm{BMI}$ or speech delays. The duration of smart device usage was not influenced by gender or parents' marital status; however, children who lived with both parents spent less time on smart devices than others. The most frequently used smart device was a tablet, and the main usage of electronic devices was for entertainment and games. Only $57.8 \%$ had parental control on smart device usage. Around half the children ate chips and candy as snacks during smart device usage. Around $60 \%$ of parents believed that smart device usage is a problem, that parents should specify time limits on using the devices and that their children are attached to the devices.

When we compare our main study results with previous studies, we notice a variation in findings. On the one hand, our results were, to some extent, similar to the previous study by Bickham et al. [11], where the authors also did not find a relationship between time spent on devices and BMI. However, they attributed the increase in BMI to the level of attention paid to the devices while being used. Furthermore, while Bickham et al. explored TV, video games and computers, they did not make the distinction of smart devices in particular.

On the other hand, in comparison to a previous Saudi study [6] where the authors indicated a positive relationship between electronic device usage and $\mathrm{BMI}$, our results indicated no such relationship. This might be explained by the previous study [6] not excluding children with chronic diseases that might act as compounding factors. The authors in that study also measured the duration of combined use of all electronic devices, including regular TV and gaming, in addition to smart devices, whereas in our study, we focused only on smart devices. Finally, Al-Agha and colleagues [6] examined the duration of time spent on smart devices within a categorical format (less than two hours and more than two hours), which might result in data distortion, while in our study, we measured time spent using smart devices using a continuous format and linear regression tests for more accurate results. We argue that our results are more focused on smart devices, but further studies are needed with different longitudinal designs to provide more accurate data.

Our study did not find a relationship between the use of smart devices and speech delays among toddlers, unlike a prior Korean study [12]. This might be because Byeon and Hong including watching TV in their assessment. This might also support our suggestion that the nature of smart device usage is different from TV, given that smart devices are more interactive than TV and, thus, may have different effects.

Although approximately two-thirds of the parents believed that smart device use was a problem, that their children were attached to the devices and that they should set specific time limits on the use of the devices, this seems to not have been reflected in their lifestyles. In fact, the average time spent on smart devices alone was 3.1 hours per day. This was higher than in another study that assessed time spent on interactive screens in the United States among children from 8 to 18 years of age, which averaged around 1.5 hours per day [16]. Our study also indicated more mean time spent on electronic devices by toddlers than in the Korean study, which showed results of around 1.3 hours per day [12]. The time spent in our study was also greater than that recommended by the American Academy of Pediatrics, which is 1 hour per day for children from 2 to 5 years of age [17]. This can put more emphasis on the spread of smart device usage among children in Saudi Arabia and highlight the need for further studies to assess other hazards that can accompany this behavior, especially when around half of the parents reported that their children had no parental control over smart device use. In addition, parents might need extra help in finding ways to decrease their children's time spent on smart devices, which could be provided via programs promoting health and through counselors and psychologists.

In addition to Al-Agha et al. [6], our study found no difference in time usage between male and female children. However, our study added that while the marital status of parents did not influence smart device usage, living with both parents meant the child was less likely to spend more time on smart devices.

Despite some expectations, the majority of parents reported that the main reason for the child's use of smart devices was for entertainment and playing games, with less attention spent on educational use. Despite this finding, $62 \%$ of the parents believed smart device use was good for educating their children. This might be taken into consideration for future studies. As one previous study noted, the content type might be a more important variable to measure than time spent using the device [13]. Thus, it could be beneficial for future studies to measure the time spent on different categories of device usage.

From another perspective, our results showed that around half the children consumed chips and candy while using smart devices. Despite this, we did not find a relationship with obesity, but this behavior could be affecting the dental health of children. Thus, another future research direction could be to assess the relationship between using smart devices and dental care.

\section{Implications}

Our study showed no significant relationships of children's use of smart devices to the negative consequences of their use, and thus, there is no need to magnify and exaggerate their impact.

This study was among the few studies that have assessed the relationship between newly emerging smart device usage and obesity, but it was the first of its kind to assess the relationship between electronic device usage and speech delay in Saudi Arabia. One of the strengths of this study was that it excluded all unhealthy patients. The limitations of this study include that it used a self-reported questionnaire, which increases the chances for bias. Additionally, we used a convenience sample, where random and multicentered samples might generate more reliable data.

\section{Conclusions}

This study concluded that despite the widespread popular belief that excessive use of smart devices can promote childhood obesity and speech development delays, we did not find any statistically significant associations between the duration of smart device use and obesity or speech delay. Nonetheless, the children in our study were found to spend more time on 
smart devices than in other countries and more than the recommended time in Saudi Arabia, especially for toddlers. Further studies are recommended to generate more generalizable data, and more studies are needed to focus on smart devices, which seem to be equivalent in importance to TV, which was the focus of most prior research. More programs could also be directed at increasing awareness of the proper use of smart devices, aimed at helping parents add more guidance to their children's use of these devices.

Acknowledgments. The authors would like to thank Dalia Aljrary, Shahad AlJifry, Reem Damanhuri, Aohoud AlNafisah, Shaima Al-Ghuraybi, Hiba Turkustani, and Bashair Al-Jubairy for helping with data collection.

Source of funding: This work was funded from the authors' own resources.

Conflicts of interest: The authors declare no conflicts of interest.

\section{References}

1. Strasburger VC, Hogan MJ, Mulligan DA, et al. Children, adolescents, and the media. Pediatrics 2013; 132(5): $958-961$.

2. Rideout VJ, Foehr UG, Roberts DF. Generation M2: media in the lives of 8-to 18-year-olds. Menlo Park (CA): Kaiser Family Foundation; 2016.

3. O'Keeffe GS, Clarke-Pearson K. The impact of social media on children, adolescents, and families. Pediatrics 2011; 127(4): 800-804.

4. Strasburger VC, Jordan AB, Donnerstein E. Health effects of media on children and adolescents. Pediatrics 2010; 125(4): 756-767.

5. Aftosmes-Tobio A, Ganter C, Gicevic S, et al. A systematic review of media parenting in the context of childhood obesity research. $B M C$ Public Health 2016; 16(1): 320, doi: doi.org/10.1186/s12889-016-2981-5.

6. Al-Agha AE, Nizar FS, Nahhas AM. The association between body mass index and duration spent on electronic devices in children and adolescents in Western Saudi Arabia. Saudi Med J 2016; 37(4): 436-439.

7. Al-Ghamdi SH. The association between watching television and obesity in children of school-age in Saudi Arabia. J Fam Community Med 2013; 20(2): 83-89.

8. Matheson DM, Killen JD, Wang Y, et al. Children's food consumption during television viewing. Am J Clin Nutr 2004; 79(6): 1088-1094.

9. Hancox RJ, Poulton R. Watching television is associated with childhood obesity: but is it clinically important? Int J Obes 2006; 30(1): $171-175$.

10. Liang $\mathrm{T}$, Kuhle S, Veugelers PJ. Nutrition and body weights of Canadian children watching television and eating while watching television. Public Health Nutr 2009; 12(12): 2457-5463.

11. Bickham DS, Blood EA, Walls CE, et al. Characteristics of screen media use associated with higher BMI in young adolescents. Pediatrics 2013; 131(5): 935-941.

12. Byeon H, Hong S. Relationship between television viewing and language delay in toddlers: evidence from a Korea national crosssectional survey. PLOS ONE 2015; 10(3): e0120663, doi: 10.1371/journal.pone.0120663.

13. Linebarger DL, Walker D. Infants' and toddlers' television viewing and language outcomes. Am Behav Sci 2005; 48(5): 624-645.

14. Christakis DA, Zimmerman FJ, DiGiuseppe DL, et al. Early television exposure and subsequent attentional problems in children. Pediatrics 2004; 113(4): 708-713.

15. Kliegman RM, Stanton BMD, Geme SJ, et al., eds. Nelson textbook of pediatrics. 20th ed. Philadelphia: Elsevier; 2015.

16. Rideout VJ, Foehr UG, Roberts DF. Generation M 2: media in the lives of 8- to 18-year-olds. Menlo Park (CA): Kaiser Family Foundation; 2010.

17. American Academy of Pediatrics. American Academy of Pediatrics announces new recommendations for children's media use. Advocacy \& Policy 2016. Available from URL: https://www.aap.org/en-us/about-the-aap/aap-press-room/Pages/American-Academy-ofPediatrics-Announces-New-Recommendations-for-Childrens-Media-Use.aspx.

Tables: 5

Figures: 0

References: 17

Received: 20.09.2018

Reviewed: 6.10 .2018

Accepted: 14.02.2019

Address for correspondence:

Shazan Borajy, MD

Batterjee Medical College

Jeddah 23819

Jeddah, Saudi Arabia

Tel.: +966566024885

E-mail: shazan.mb@hotmail.com 